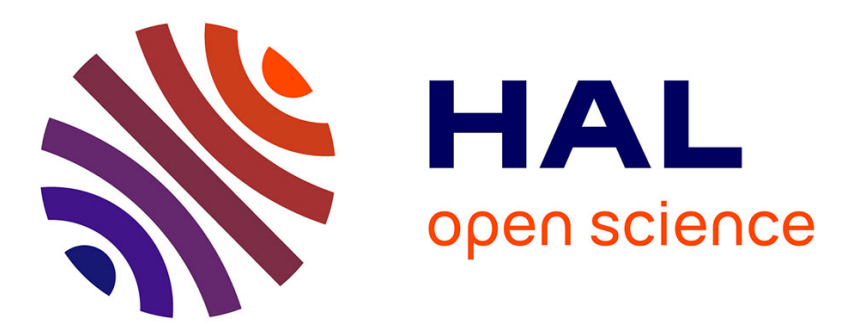

\title{
Levels in 192Os excited by the (p, p') and (d, d') reactions
}

J. Jastrzebski, R. Kaczarowski, J. Lukasiak, S. André, J. Treherne

\section{To cite this version:}

J. Jastrzebski, R. Kaczarowski, J. Lukasiak, S. André, J. Treherne. Levels in 192Os excited by the (p, p') and (d, d') reactions. Journal de Physique, 1976, 37 (12), pp.1383-1385. 10.1051/jphys:0197600370120138300 . jpa-00208538

\section{HAL Id: jpa-00208538 https://hal.science/jpa-00208538}

Submitted on 1 Jan 1976

HAL is a multi-disciplinary open access archive for the deposit and dissemination of scientific research documents, whether they are published or not. The documents may come from teaching and research institutions in France or abroad, or from public or private research centers.
L'archive ouverte pluridisciplinaire HAL, est destinée au dépôt et à la diffusion de documents scientifiques de niveau recherche, publiés ou non, émanant des établissements d'enseignement et de recherche français ou étrangers, des laboratoires publics ou privés. 


\title{
LEVELS IN ${ }^{192}$ Os EXCITED BY THE (p, $\left.p^{\prime}\right)$ AND (d, d') REACTIONS $\left({ }^{*}\right)$
}

\author{
J. JASTRZEBSKI, R. KACZAROWSKI, J. LUKASIAK \\ Institute for Nuclear Research, Department of Physics, 05-400 Swierk, Poland \\ and \\ S. ANDRÉ, J. TREHERNE \\ Institut des Sciences Nucléaires, BP 257, 38044 Grenoble Cedex, France
}

(Reçu le 23 juillet 1976, accepté le 23 août 1976)

\begin{abstract}
Résumé. - Les niveaux d'énergie de ${ }^{192}$ Os ont été étudiés par réactions $\left(p, p^{\prime}\right)$ et $\left(d, d^{\prime}\right)$. Les spectres $\gamma$ et les coïncidences $\gamma-\gamma$ ont été enregistrés à des énergies de protons de $16 \mathrm{MeV}$ et de deutons de 23,2 MeV. En dehors des niveaux déjà connus, des états de parité négative ont été observés. La possibilité d'une forme triaxiale pour ce noyau est envisagée.
\end{abstract}

\begin{abstract}
The energy levels of ${ }^{192}$ Os were studied by the (p, $\left.p^{\prime}\right)$ and $\left(d, d^{\prime}\right)$ reactions. Single gamma ray spectra and $\gamma-\gamma$ coincidences were measured at $16 \mathrm{MeV}$ (protons) and 23.2 MeV (deuterons) incident energy. Negative parity states were observed in addition to previously known levels. The possiblity of the triaxial shape for this nucleus is discussed.
\end{abstract}

1. Introduction. - Levels of the heaviest stable osmium isotope ${ }^{192} \mathrm{Os}$ are known from the decay of $5.9 \mathrm{~s}$ isomeric state in this nucleus, excited by the $\left(\mathrm{n}, \mathrm{n}^{\prime}\right)$ reaction [1], from Coulomb excitation experiments [2, 3] and from ${ }^{192} \operatorname{Re}[1]$ and ${ }^{192} \operatorname{Ir}$ [4] decays.

This paper reports the results obtained during in-beam studies of ${ }^{191} \mathrm{Ir}$ by $(\mathrm{p}, 2 \mathrm{n})$ and $(\mathrm{d}, 3 \mathrm{n})$ reactions on a ${ }^{192}$ Os target [5]. A number of gamma transitions could be attributed to the target excitation.

2. Experimental procedure and results. 2.1 EXPERIMENTAL SET-UP. - The metallic Os target (enriched to $99 \%{ }^{192} \mathrm{Os}$ ), approximately $20 \mathrm{mg} / \mathrm{cm}^{2}$ thick, deposited on $2 \mathrm{mg} / \mathrm{cm}^{2}$ mylar backing was irradiated with $16 \mathrm{MeV}$ protons and $23.2 \mathrm{MeV}$ deuterons from the Grenoble variable energy cyclotron. Single gamma-ray spectra and $\gamma-\gamma$ coincidences were measured with 45 and $77 \mathrm{~cm}^{3} \mathrm{Ge}(\mathrm{Li})$ detectors. Details of the experimental arrangement were published previously [6] and will not be further discussed here.

The list of gamma lines belonging to ${ }^{192} \mathrm{Os}$ is presented in table I. Attribution of the transitions to this nucleus was made on the basis of coincidences

$\left(^{*}\right)$ This work was performed within the Grenoble-Swierk collaboration. with lines placed in the decay scheme of the $5.9 \mathrm{~s}$ isomeric state [1].

Some typical coincidence spectra are shown in figure 1.

2.2 LEVEL SCHEME. - The level scheme deduced from the coincidence data is presented in figure $2 a$. This scheme is in good agreement with that proposed in ref. [1]. At most three levels of the rotational bands built on the ground, $K \mathrm{I}^{\pi}=22^{+}$and $44^{+}$states are fed at the projectile energies used. But we report a $3^{-}, 1341 \mathrm{keV}$ state and the first member of its rotational band $\left(\mathrm{I}^{\pi}=4^{-}, E=1560.6 \mathrm{keV}\right)$. Our attribution of spin and parity to these levels is based on their decay modes and on the negative parity state systematics in the even Os nuclei shown in figure 3.

Figure $2 b$ shows the cross-sections for the excitation of some levels in ${ }^{192} \mathrm{Os}$. Their relative values are based on the intensity balance for each level. The absolute cross-section was estimated by comparison of the intensities of the transitions feeding the ${ }^{191} \mathrm{Ir}$ ground state in the ( $\mathrm{p}, 2 \mathrm{n})$ and $(\mathrm{d}, 3 \mathrm{n})$ reactions, with the crosssections predicted for these reactions by the hybrid model [7]. For bombarding energies near the maximum of the excitation function these predictions should be correct within $20 \%$ accuracy. 


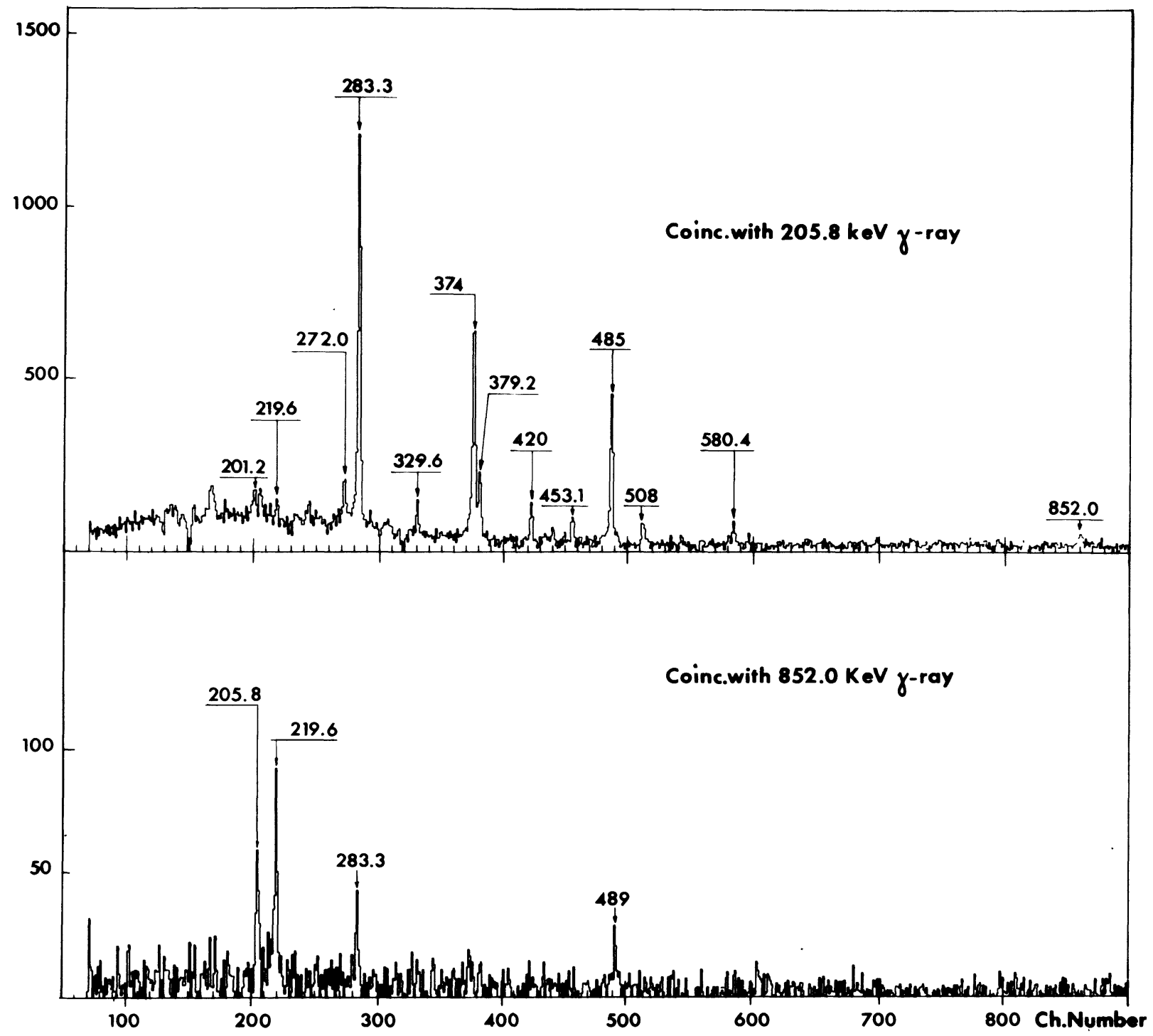

FIG. 1. - Typical coincidence spectra.

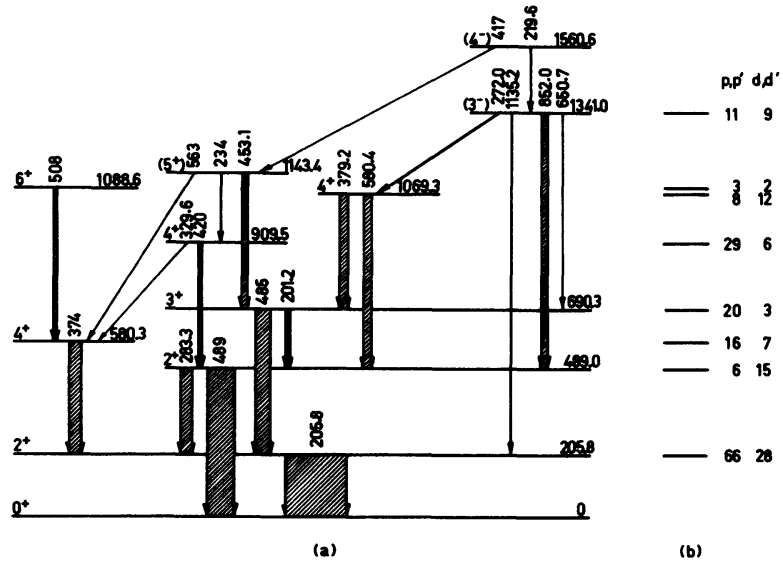

FIG. 2. - a) Levels in ${ }^{192}$ Os excited in (p, $\left.\mathrm{p}^{\prime}\right)$ and (d, $\left.\mathrm{d}^{\prime}\right)$ reactions. b) Absolute cross-sections (in $\mathrm{mb}$ ) for the excitation of some levels.

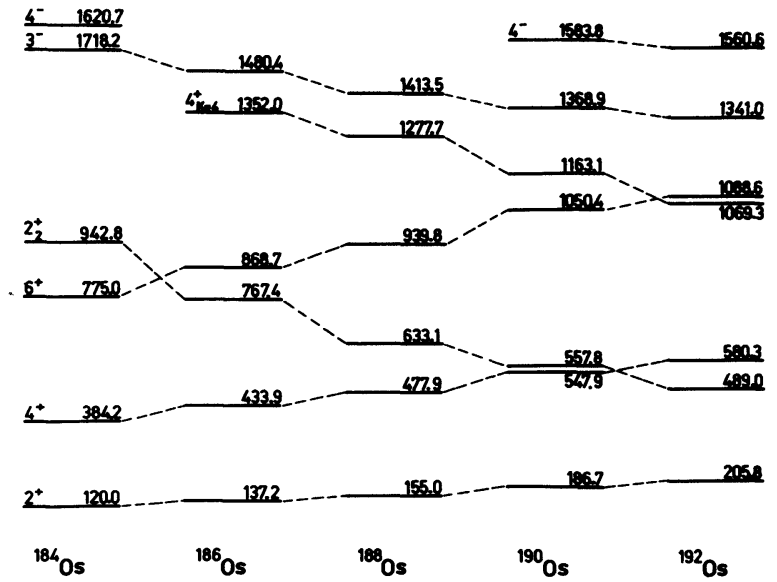

FIG. 3. - Level systematics in even osmium isotopes. 


\section{TABLE I}

The energies and relative intensities of $\gamma$-rays observed in the $\left(\mathrm{p}, \mathrm{p}^{\prime}\right)$ and $\left(\mathrm{d}, \mathrm{d}^{\prime}\right)$ reactions on ${ }^{192}$ Os target

\begin{tabular}{|c|c|c|c|c|}
\hline \multirow{3}{*}{$\begin{array}{c}\text { Energy }\left({ }^{a}\right) \\
(\mathrm{keV}) \\
-\end{array}$} & \multicolumn{2}{|c|}{ Relative intensity $\left({ }^{b}\right)$} & \multirow{2}{*}{\multicolumn{2}{|c|}{$\begin{array}{l}\text { Placement } \\
\quad(\mathrm{keV})\end{array}$}} \\
\hline & $\left(\mathrm{p}, \mathrm{p}^{\prime}\right)$ & $\left(d, d^{\prime}\right)$ & & \\
\hline & - & - & - & \\
\hline 168.4 & (c) & $26(4)$ & & \\
\hline 201.2 & $47(4)$ & $48(4)$ & $690.3 \rightarrow$ & 489.0 \\
\hline 205.8 & 1000 & 1000 & $205.8 \rightarrow$ & 0 \\
\hline $219.6\left(^{d}\right)$ & $10(5)$ & $10(5)$ & $1560.6 \rightarrow 1$ & 1341.0 \\
\hline $234\left(^{c}\right)$ & $3(1)\left({ }^{f}\right)$ & $4(1)\left({ }^{f}\right)$ & $1143.4 \rightarrow$ & 909.5 \\
\hline 242.4 & $70(10)$ & $129(9)$ & & \\
\hline 272.0 & $34(6)$ & $53(4)$ & $1341.0 \rightarrow 1$ & 1069.3 \\
\hline 283.3 & $176(7)$ & $224(16)$ & $489.0 \rightarrow$ & 205.8 \\
\hline 329.6 & $67(10)$ & $29(3)$ & $909.5 \rightarrow$ & 580.3 \\
\hline 348.5 & & $26(4)$ & & \\
\hline $374\left(^{(d)}\right.$ & $220(80)\left({ }^{e}\right)$ & $220(80)\left({ }^{e}\right)$ & $580.3 \rightarrow$ & 205.8 \\
\hline 379.2 & $37(9)$ & $156(17)$ & $1069.3 \rightarrow$ & 690.3 \\
\hline $417\left(\left(^{(, d}\right)\right.$ & & & $1560.6 \rightarrow 1$ & 1143.4 \\
\hline $420\left(^{d}\right)$ & $220(20)\left({ }^{f}\right)$ & $100(15)\left({ }^{f}\right)$ & $909.5 \rightarrow$ & 489.0 \\
\hline 437 & $16(5)$ & $16(5)$ & & \\
\hline 453.1 & $86(12)$ & $107(12)$ & $1143.4 \rightarrow$ & 690.3 \\
\hline $485\left(^{(d)}\right.$ & $270(30)\left({ }^{f}\right)$ & $270(30)\left({ }^{f}\right)$ & $690.3 \rightarrow$ & 205.8 \\
\hline $489\left(^{d}\right)$ & $235(30)\left({ }^{f}\right)$ & $430(40)(f)$ & $489.0 \rightarrow$ & 0 \\
\hline $508\left(^{d}\right)$ & $30(10)\left({ }^{e}\right)$ & $45(15)\left({ }^{e}\right)$ & $1088.6 \rightarrow$ & 580.3 \\
\hline $563\left({ }^{(}\right)$ & $18(2)\left({ }^{f}\right)$ & $22(2)\left({ }^{f}\right)$ & & \\
\hline 580.4 & $88(12)$ & $142(15)$ & $1069.3 \rightarrow$ & 489.0 \\
\hline $591\left({ }^{(}\right)$ & & & & \\
\hline 650.7 & weak & $24(4)$ & $1341.0 \rightarrow$ & 690.3 \\
\hline 852.0 & $72(10)$ & 91(11) & $1341.0 \rightarrow$ & 489.0 \\
\hline 1135.2 & $(g)$ & 24(4) & $1341.0 \rightarrow$ & 205.8 \\
\hline
\end{tabular}

$\left({ }^{a}\right)$ Energy error $\cdot$ is $0.1 \mathrm{keV}$ for strong and well resolved lines and can attain $0.8 \mathrm{keV}$ for weak or badly resolved transitions.

${ }^{(b)}$ Values are given for $16 \mathrm{MeV}$ and $23.2 \mathrm{MeV}$ incident energy of protons and deuterons, respectively. Uncertainties in the least significant figures are given in parentheses.

$\left.{ }^{(}{ }^{c}\right)$ Line observed in coincidence spectra only.

(d) Complex line.

$\left({ }^{e}\right)$ Estimated from the coincidence spectra.

$(f)$ Calculated from the branching ratio of transitions deexciting the given level [1].

$\left({ }^{g}\right)$ Out of energy range.
3. Discussion. - The $3^{-}$and $4^{-}$states in ${ }^{192}$ Os at $1341 \mathrm{keV}$ and $1560.6 \mathrm{keV}$ respectively were not found in the decay studies [1, 3, 4]. It seems likely that the former is identical to the $3^{-}, 1333 \mathrm{keV}$ state observed in the inelastic scattering of $\alpha$ particles and reported by Baker et al. [3] during the preparation of our note.

Comparison of the branching ratios for the decay of $3^{-}$state with the predictions of the Alaga rule is presented in table II. The best agreement is found

\section{TABLE II}

E1 transitions from the $3^{-}$state to the $K=2$ band in ${ }^{192} \mathrm{Os}$

\begin{tabular}{ccccc} 
& \multicolumn{5}{c}{$\mathrm{B}(\mathrm{E} 1)$ (relative) } \\
Transition & Exp. & $K_{\mathrm{i}}=1$ & $K_{\mathrm{i}}=2$ & $K_{\mathrm{i}}=3$ \\
$-\overline{3^{-}}$ & - & $-\overline{0}$ & $-\overline{0}$ & - \\
$3^{-}, K_{\mathrm{i}} \rightarrow 2^{+}, K_{\mathrm{f}}=2$ & 1.0 & 1.0 & 1.0 & 1.0 \\
$3^{-}, K_{\mathrm{i}} \rightarrow 3^{+}, K_{\mathrm{f}}=2$ & $0.59 \pm 0.12$ & 8.87 & 1.40 & 0.35 \\
$3^{-}, K_{\mathrm{i}} \rightarrow 4^{+}, K_{\mathrm{f}}=2$ & $<0.3$ & 11.4 & 1.80 & 0.05
\end{tabular}

for the assumption of $K=3$ for the level considered. This supports the interpretation of the $3^{-}$state as the octupole one, as in the lighter osmium isotopes [8]. However, the $3^{-}$state in ${ }^{192} \mathrm{Os}$ decays also to the $K I^{\pi}=02^{+}(205.8 \mathrm{keV})$ level with a branching ratio : $B(\mathrm{E} 1,1135.2 \mathrm{keV}) / B(\mathrm{E} 1,852.0 \mathrm{keV})=0.11$. So in this case $K$ is not a good quantum number. This fact may be due to the triaxiality of the ${ }^{192} \mathrm{Os}$ nucleus. Such assumption can also explain the inversed order of $K \mathrm{I}^{\pi}=22^{+}$and $04^{+}$levels (cf. Fig. 3) in this isotope.

Acknowledgements. - Our thanks are due to Dr. N. Kaffrell for his comments on ${ }^{192 \mathrm{~m}}$ Os decay.

\section{References}

[1] KAfFrell, N. and HerzoG, W., unpublished data, quoted after SCHMORAK, M. R., Nucl. Data Sheets 9 (1973) 195.

[2] Milner, W. T., McGowan, F. K., Robinson, R. L., StelSON, P. H. and SAYER, R. O., Nucl. Phys. A 177 (1971) 1.

[3] Baker, P. T., Kruse, T. H., Hartwig, W., Lee, I. Y. and Saladin, J. X., Nucl. Phys. A 258 (1976) 43.

[4] Prasad, R., Chaturvedi, L., Chaturvedi, S. N. and Nigam, A. K., Nucl. Phys. A 243 (1975) 317

[5] André, S., Jastrzebski, J., Kaczarowski, R., Lukasiak, J., Rivier, J., Sebille-Schück, C. and Treherne, J., Proc. Symposium on Highly Excited States in Nuclei, Jülich (1975) p. 67 and to be published.
[6] ANDrÉ, S., Boutet, J., Rivier, J., Treherne, J., JASTRzebsKi, J., Lukasiak, J., Sujkowski, Z. and Sebille-Schück, C., Nucl. Phys. A 243 (1975) 229.

[7] Blann, M. and Mignerey, A., Nucl. Phys. A 186 (1972) 245.

[8] Yamazaki, T., Nishiyama, K. and Hendrie, D. L., Nucl. Phys. A 209 (1973) 153;

Hochel, R., Daly, P. J. and Hofstetter, K. J., Nucl. Phys. A 211 (1973) 165 ; Yates, S. W., Cunnane, J. C., Hochel, R. and DalY, P. J., Nucl. Phys. A 222 (1974) 301 ;

Yates, S. W., Cunnane, J. C. and Daly, P. J., Phys. Rev. C 11 (1975) 2034 ; Yates, S. W., Cunnane, J. C., Daly, P. J., Thompson, R. and Sheline, R. K., Nucl. Phys. A 222 (1974) 276 